\title{
Efficient Spiral algorithm for Cutting Bit mapping on the Micro Trencher Blade
}

\author{
[Aqib Perwaiz, Almas Anjum, Anees Ahmad and Sheraz Mehfooz]
}

\begin{abstract}
This paper presents a novel algorithm for placement of circular cutting bits on a 141.36 inch circular trencher blade for hard rock cutting to be able to lay fiber optic cable of varying width. The blade is divided into $6 \mathrm{x}$ segments of 60 degree each. The spiral algorithm calculates the exact angle of hit, no. of bits and the angle of exposure to precisely cut the required width of hard rock patch for fiber optic cable lying. With the no. of bits and angle known the best cutting blade speed and speed of wheeled machine can be calculated to obtain précised outcome. Given the type of material to cut the algorithm can also estimate based on the above mentioned parameters the running cost of trenching blades/ $\mathrm{km}$ in terms of bits replacement to forecast the exact cost of trenching.
\end{abstract}

The algorithm simulation on hard rock shows as the no. of bits are reduced on the circular trencher blade the bits replacement rate / $\mathrm{km}$ increases, the effect is even worse if simultaneously the bit ground penetrating angle is made wider. The effects are inversely proportional if the no. of bits is increased and the bit ground penetrating angle is made narrower. But there is a limit the $n$. of bits can be increased and the angle can be made narrower, beyond that limit the effect is not optimized.

An already existing micro trencher by Ditch witch has been studied as a case study to compare the on ground performance and simulation performance. The test was conducted at CPEC route in Gilgit Pakistan.

Keywords-Component, Trenching, cutting bits, circulat blade, rpm, speed, Micro trencher, Mean Time to Failure ( MTF).

\section{INTRODUCTION}

A trencher or micro trencher is a type of equipment in construction industry to dig trenches for laying of cables, pipes etc. The trencher can also be used in the trench warfare preparation. Based on the requirement the trenchers vary in sizes and based on the area of operation the trencher varies in the type of mobility i.e wheeled or tracked. A trencher can be a

Aqib Perwaiz, Almas Anjum, Sheraz Mehfooz

NUST College of Electrical and Mechanical Engineering

Islamabad, Pakistan

Anees Ahmed

TouchStone Solutions

Islamabad

Pakistan self-propelled unit or use a prime mover to carry out the task [1]. A circular or saw of wheeled carries some cutting bits placed along the circumference of the when at different angles. The other type is a saw type trencher which is used for soft soil, being used in soft soil it has less operating cost [2][3]. For wheeled trencher the cutting wheel works by clearing the soil as is done in case of bucket-wheel. Consequently, it will be less sensitive to the presence of blocks in the soil [8][9]. Wheeled trenchers are also used to cut pavement for road maintenance and to gain access to utilities under roads. Wheeled trencher for micro trench widths which range from about 30 to $130 \mathrm{~mm}(1.2$ to $5.1 \mathrm{in})$ with a depth of $500 \mathrm{~mm}$ (20 in) or less are termed as micro trencher. With a micro trencher, the structure of the road is maintained and there is no associated damage to the road[4]. Owing to the reduced trench size, the volume of waste material excavated is also reduced. Micro trenchers are used to minimize traffic or pedestrian disturbance during network laying[5]. A micro trencher can work on sidewalks or in narrow streets of cities, and can cut harder ground than a chain trencher, including cutting through solid stone. They are also used to cut pavement for road maintenance and to gain access to utilities under roads.

Due to its design the wheel may reach variable cutting depths with the same tool, and can keep a constant soil working angle with a relatively small wheel diameter[6][7] (which reduces the weight and therefore the pressure to the ground, and the height of the unit for transport).

The cutting bits (6 to 9 depending on the diameter) are placed around the wheel, and bear the teeth which are more or less dense depending on the ground they will encounter. These tools can be easily changed manually, and adjusted to allow different cutting widths on the same wheel. The teeth are placed in a semi-spherical configuration to increase the removal of the materials from the trench. The teeth are made of high strength steel (HSLA steel, tool steel or high speed steel) or cemented carbide. Under heavy use the teeth's are required to be replaced periodically. This counts for the running cost of the trencher.

\section{Design Evaluation}

\section{A. Design Parameters}

For designing a micro trenching machine, there are few parameters as enlisted below which play a vital role in the designing and optimized application of the bits placement algorithm on the circular wheel. 
Proc. of the Sixth International Conference on Advances in Mechanical and Robotics Engineering - AMRE 2017. Copyright (C) Institute of Research Engineers and Doctors. All rights reserved.

ISBN: 978-1-63248-140-5 doi: 10.15224/ 978-1-63248-140-5-35

- Type of hard rock to cut (material testing of the hard rock is required to dictate the no of bits in each segment)

- $\quad$ Lay Depth of the cut

- Width of the cut

- Cutting speed

- $\quad$ Forward moving speed

- Working road conditions

- Inclination of road

\section{B. Mathematical Model of Micro tencher Blade}

The general shape (360 degree view) and geometry are shown in fig 1 . The micro trencher is attached with a wheeled machine moving with a speed of $\mathrm{V} \mathrm{m} / \mathrm{s}$ and the micro trencher is mounted on a pivot point at a height $\mathrm{H}$ from the ground. The micro trencher has six segments over the circular wheel $(23.56$ inch).
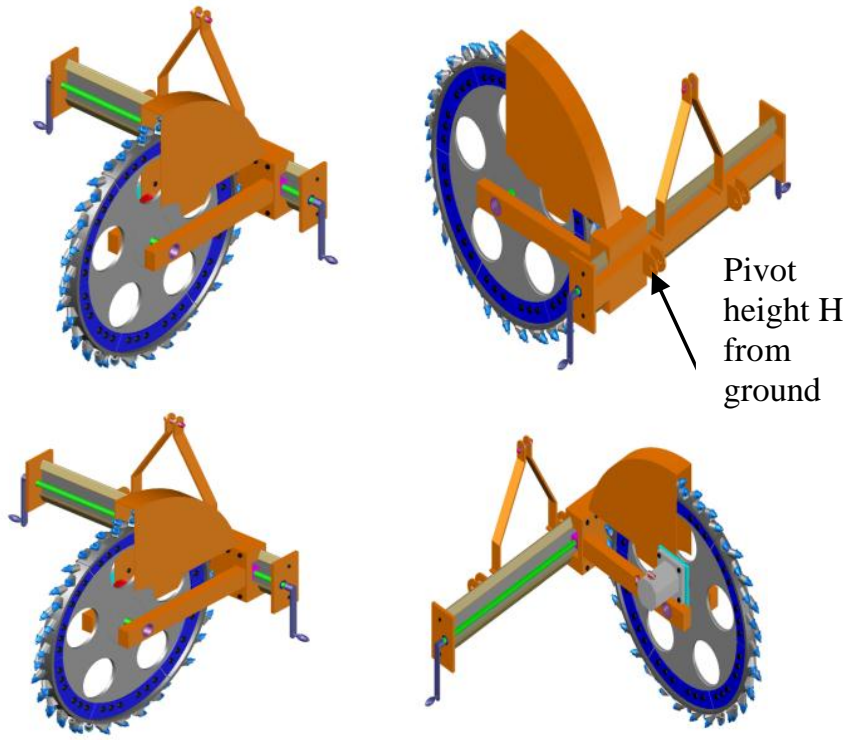

Figure 1 Force diagram and geometry of a circular micro trencher blade

Within each 60 degree of the trencher blade there can be 6 - 9 bits in different orientations. The different bit orientation settings give us a room to maneuver between the trench width, MTF and cutting depth. Exact width can be trenched to control the decrease the refilling of concrete after the cable laying. The refilling has been an important point as it incurs extra cost on the contracting agency. Precise cutting can save this extra cost.

\section{CutTing Blade Bits Placement SPIRAL ALGORITHM}

The strength of the material undercut dictates the strength and placement of the bits. The circular diameter of the blade is also related with the bit placement algorithm. The material to be trenched (hard rock in our case) was tested and it revealed that the strength of hard rock is nearly $4 \times$ Tons and an equivalent force is required to initiate the process cutting process, the algorithm also widens the bits gap by adjusting the bit angles to meet the trench width requirement. As a thumb rule the half diameter of the trencher blade represents the approximate depth of cutting. The bits used in the cutting process are as shown in Fig 2. The bits are mounted on a base which sets the direction and angle of impact on the $2 \mathrm{~d}$ plane. The bits are spring loaded from sides for tight fitting into the base. The bit is designed to give point impact at the surface. The bit placement is so done so that at the end the whole wheel is balanced i.e the positive and negative oscillations in each segment are balanced out for optimum performance and alignment of the trencher blade.

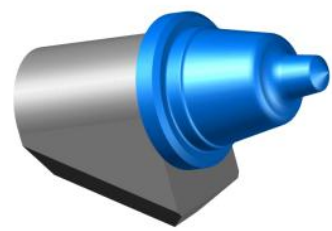

Figure 2 Cutting Bit with Base

The placement of $6-9$ bits was done using the slightly modified equiangular spiral algorithm

The equation of Equiangular (or logarithmic spiral in Polar Coordinates is given by

$$
r=a e^{b \theta}
$$

where $r$ is the distance from the Origin, $\theta$ is the angle from the $\mathrm{x}$-Axis, and $\mathrm{a}$ and $\mathrm{b}$ are arbitrary constants. It can be expressed parametrically using

$$
\operatorname{Cos} \theta=\frac{1}{\sqrt{1-\tan ^{2} \theta}}=\frac{1}{\sqrt{1+\frac{y^{2}}{x^{2}}}}=\frac{x}{\sqrt{x^{2}+y^{2}}}=\frac{x}{r}
$$

which gives

$$
\begin{aligned}
& x=r \cos \theta=a \cos \theta e^{b \theta} \\
& y=r \sin \theta=a \sin \theta e^{b \theta}
\end{aligned}
$$

The logarithmic spiral can be constructed from equally spaced rays by starting at a point along one ray, and drawing the perpendicular to a neighboring ray. As the number of rays 
approached infinity, the sequence of segments approaches the smooth logarithmic spiral.

The rate of change of radius is given as under:-

$$
\frac{d r}{d \theta}=a b e^{b \theta}=b r
$$

and the Angle between the tangent and radial line at the point is $(\mathrm{r}, \theta)$ is defined as $\varphi$

$$
\begin{aligned}
& \varphi=\tan ^{-1}\left(\frac{r}{\frac{d r}{d \theta}}\right)=\tan ^{-1}\left(\frac{1}{b}\right)=\cot ^{-1} b \\
& b \rightarrow o
\end{aligned}
$$

As $b \rightarrow o$ the spiral approaches a circle. The random evaluation bit pattern of trencher blade is shown in fig 3 .

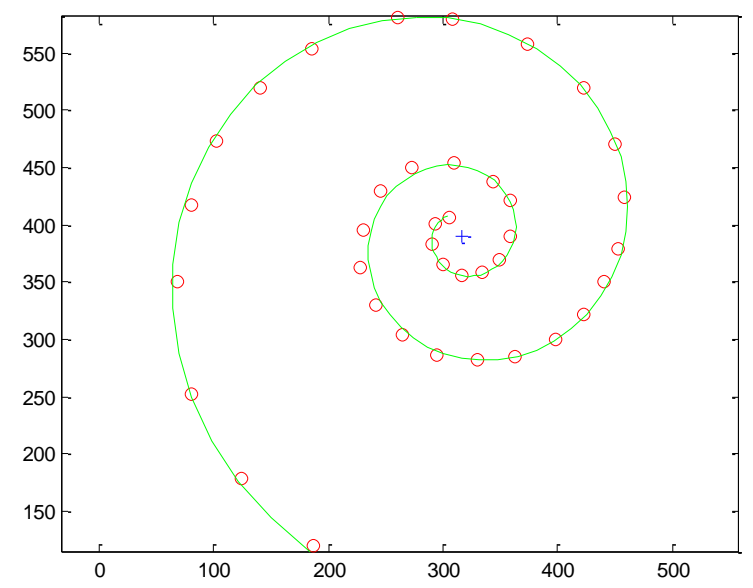

Figure 3 Random bit pattern of bits on trencher blade

There are $2 \mathrm{x}$ spirals origination from the same start lagging the spiral 1 by a certain degree to map the bits on the circular cutting blade segment. With in the 360 degrees of circular cutting blade there were 6 segments of 60 degree each i.e the random bit pattern is to be replicated six times. With in each segment there is a gap on 0.125 inch. With in each segment of 60 degree there have been $6-9$ bits simulated as shown in fig 4.
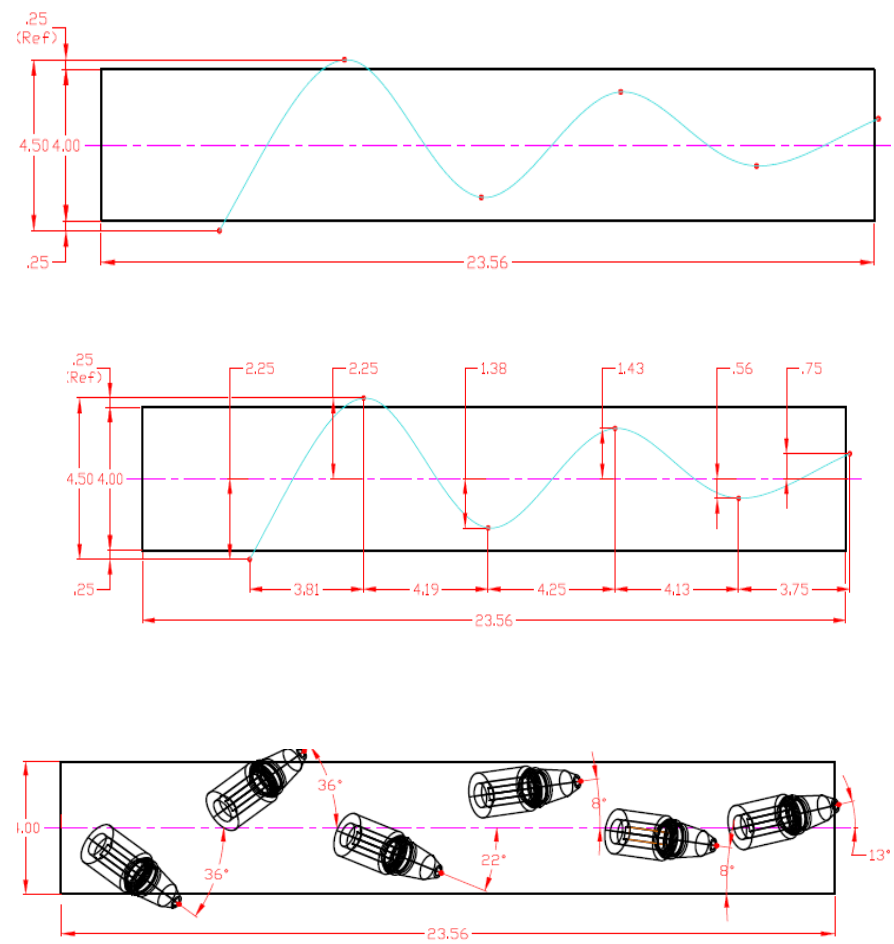

(a)
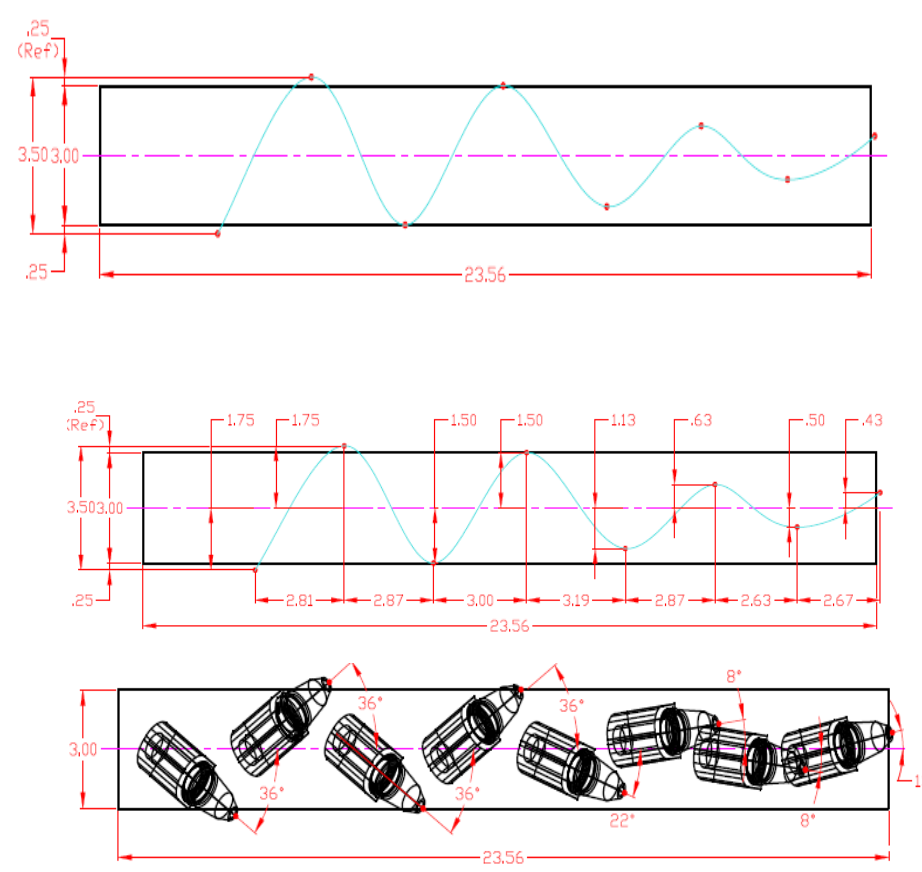

(b) 
Proc. of the Sixth International Conference on Advances in Mechanical and Robotics Engineering - AMRE 2017.

Copyright (C) Institute of Research Engineers and Doctors. All rights reserved.

ISBN: 978-1-63248-140-5 doi: 10.15224/ 978-1-63248-140-5-35
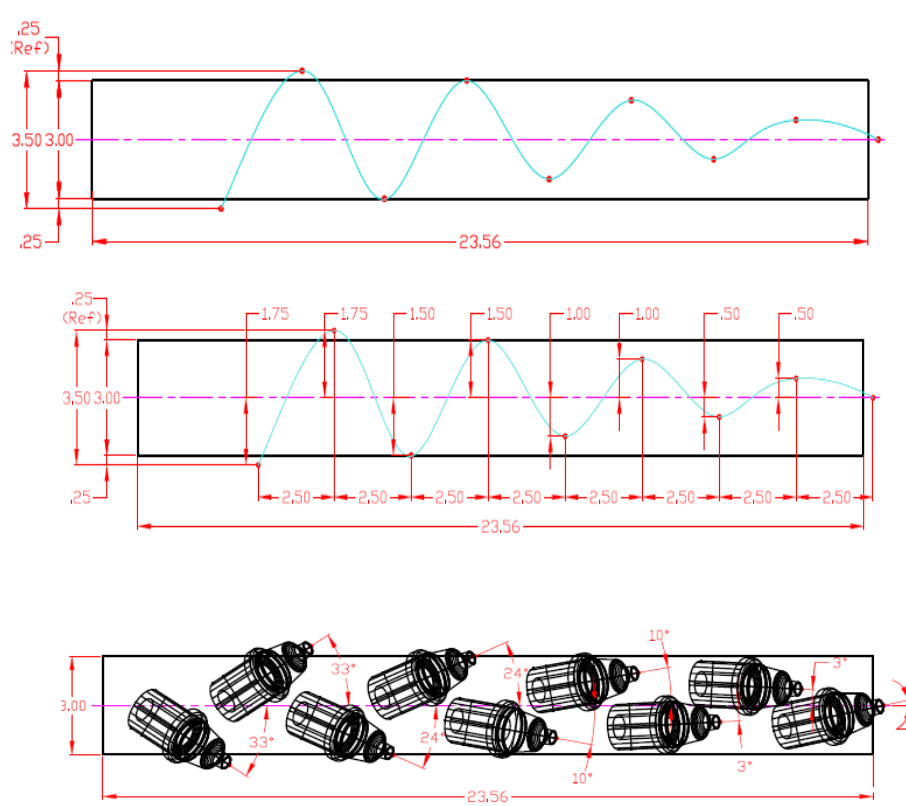

(c)

Figure 4. (a) 6 bit pattern on 4 inch width (b) 8 bit pattern on 3 inch width (c) 9 bit pattern on 3 inch width

The blade dia is 141.36 inches and the length of each segment is 23.56 inches and width is $3-4$ inch. The degree of cutting bits map on the width of the trench, for multiple design the starting degrees vary from 12-13 degrees. The Spiral shown in Fig 1 is stretched across the surface of the trencher blade to map the bits. Based on the requirement the width of the blade top segment is designed. Same blade can house multiple widths top segments as well. Multiple widths will indicate multiple trench width requirements

\section{HARD ROCK TESTING}

Hard rock testing is an essential part of the design as the testing report will dictate the outcome of the design. Concrete having a strength of 40000 psi was simulated and the results reveals some facts and design considerations. The results are shown in Table 1.

TABLE I. PER KM RUNNING COST

\begin{tabular}{|c|c|c|c|c|}
\hline \multirow{3}{*}{ Design } & \multicolumn{4}{|c|}{ Per Km Running Cost } \\
\cline { 2 - 5 } & BIT MTF & $\begin{array}{c}\text { BIT } \\
\text { unit } \\
\text { Cost \$ }\end{array}$ & $\begin{array}{c}\text { Total } \\
\text { BIT } \\
\text { cost \$ }\end{array}$ & $\begin{array}{c}\text { Running } \\
\text { Cost/Km }\end{array}$ \\
\hline Fig4(a) & $\begin{array}{l}\text { After 75 meters 12-16 } \\
\text { bits were damaged }\end{array}$ & 12 & $\begin{array}{c}144- \\
192\end{array}$ & $\begin{array}{c}1920- \\
2559.36\end{array}$ \\
\hline
\end{tabular}

\begin{tabular}{|c|c|c|c|c|}
\hline \multirow[b]{2}{*}{ Design } & \multicolumn{4}{|c|}{ Per Km Running Cost } \\
\hline & BIT MTF & $\begin{array}{c}\text { BIT } \\
\text { unit } \\
\text { Cost } \$\end{array}$ & $\begin{array}{c}\text { Total } \\
\text { BIT } \\
\text { cost } \$\end{array}$ & $\begin{array}{l}\text { Running } \\
\text { Cost/Km }\end{array}$ \\
\hline Fig4(b) & $\begin{array}{l}\text { After } 200 \text { meter } 7-10 \\
\text { bits were damaged }\end{array}$ & & $84-120$ & $420-600$ \\
\hline Fig4(c) & $\begin{array}{l}\text { After } 500 \text { meter } 5-7 \\
\text { bits were damaged }\end{array}$ & & $60-84$ & $120-168$ \\
\hline
\end{tabular}

For the simulation the cutting was carried out at 20 inch depth @ 120 yards/ hr. Adding more no. of BITS in Fig4(c) design yield to rock parts striking among the bits there by increasing the failure rate.

\section{RESULTS}

The results show that for hard rock or concrete having 40000 psi strength the best and economical design is having 9 bits placed as per fig 4(c), this will give a robust design option for long term use before a failure occurs.

\section{References}

[1] Advantages and limitations of using chain trenchers in rock, Pipelines International September 2009

[2] Mellor, M., "Mechanics of Cutting and Boring - Part I Kinematics of Transverse Rotation Machines”, CRREL Special Report 226, 1975.

[3] Mellor, M., "Mechanics of Cutting and Boring - Part III Kinematics of Continuous Belt Machines", CRREL Special Report 76-17, 1976.

[4] Mellor, M., Mechanics of Cutting and Boring - Part IV Dynamics and Energetics of Transverse Rotation Machines, CRREL Special Report 777, 1977.

[5] Mellor, M., "Mechanics of Cutting and Boring - Part VIII Dynamics and Energetics of Continuous Belt Machines", CRREL Special Report 7811, 1978.

[6] Sitorus, P.E., Ko, J.H., Kwon, O.S., “Analytical design of chain trenching machine for underwater construction robot at UCRC-KIOST", Conference on Marine Robot Technology, Pukyong National University, Pusan, Korea, 28-29 April, 2016.

[7] Goktan, R.M., and Gunes, N., "A Semi-empirical Approach to Cutting Force Prediction for Point-Attack Picks", The Journal of the South African Institute of Mining and Metallurgy, Vol. 105, pp. 257-264

[8] Patar Ebenezer Sitorus and Jin Hwan Ko,"Parameter Study of Chain Trenching Machines of Underwater Construction Robots via Analytical Model" OCEANS'16 MTS/IEEE Monterey, CA, US

[9] JH Ko, OS Kwon,"Analytical Design of Chain Trenching Machine for Underwater Construction Robot",UCRC-KIOST PE Sitorus, Conference on Marine Robot Technology, Pukyong National University, Busan 2016 


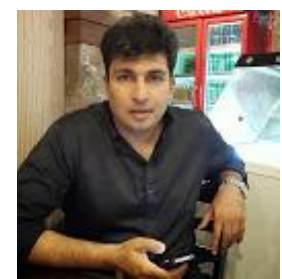

Aqib Perwaiz received the PhD degree from National University of Sciences and Technology, Islamabad, Pakistan. He is currently assistant director Research and development at College of Electrical and Mechanical Engineering, National University of sciences and Technology, Islamabad. His research interests include Software Defined Radio, reverse engineering, design thinking and data mining. He has 21 years of industrial experience and has been reviewing the research papers and reports of many international conferences and journals.

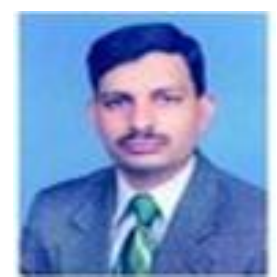

Almas Anjum received the PhD degree from National University of Sciences and Technology, Islamabad, Pakistan. He is currently Director Research and development at College of Electrical and Mechanical Engineering, National University of sciences and Technology, Islamabad. His research interests include Image processing, system design and wavelet transforms. He has considerable experience and many international publications to his name. He has been reviewing the technical papers and reports of many international conferences and journals.

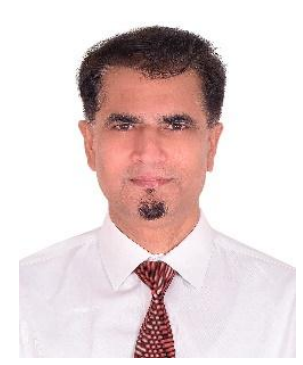

Anees Ahmad received his PhD from Marquette University/BSU (USA). His area of research is reliability in Engineering Design. He has Twenty seven (27) years of industrial and academic experience with focus on Design for Manufacture and Assembly (DFMA). He has served in various industries including OptoMechanical, electro-optics, Industrial Test Equipment, Automotive, Alternative Energy/solar, Processing Industry and Telecommunication. He has also served as a College Facility at and part of curriculum advisory committee at ITT Technical Institute (Chicago, IL), ORT Technical Institute (Chicago, IL) and Manhattan Technical Institute (New York, NY). He also has contributions in US patton - 5,303,322:

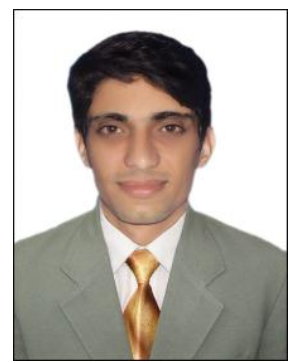

Sheraz Mehfooz received his Bachelor degree from International Islamic University, Islamabad, Pakistan. Currently he is working as a research assistant in Research and Development department at College of Electrical and Mechanical Engineering, National University of Sciences and Technology, Islamabad. His research interest focus on embedded system, Virtual reality and real time simulation design for hardware. He has received certificate of International CST Workshop on EM Solver and Antenna design. He has good experience of antenna designing, testing and real time electromagnetic wave simulation. 